\title{
Nutritional and other influences in childhood as predictors of adult obesity
}

\author{
Chris Power* and Tessa Parsons \\ Department of Epidemiology and Public Health, Institute of Child Health, 30 Guilford Street, London WC1N 1EH, UK
}

\begin{abstract}
It has been proposed that there are critical periods during childhood that influence the development of obesity, including gestation and early infancy, the period of adiposity rebound that occurs between ages 5 and 7 years, and adolescence. Despite an extensive literature, there is to date only modest evidence for most of the factors such as nutrition, physical activity and other behavioural factors that are suspected as playing a role in the development of obesity. A recent review of this evidence (Parsons et al. 1999) showed, however, a consistent relationship between socio-economic status (SES) of origin and adult obesity, whereby those from lower SES backgrounds were fatter subsequently in adulthood. This association appeared to apply to both men and women, a finding that contrasts with the trends observed in cross-sectional studies, of an association with SES for women only. There are several potential explanations for the SES of origin-adult obesity relationship. SES of origin may be confounded by parental body size; studies to date provide insufficient evidence of an independent association with SES after allowing for parental body size. Alternatively, environment in early life (for which SES of origin is a proxy measure) may have a long-term impact on obesity later in adulthood, through one or more of several processes. Three major potential explanations can be identified: (1) nutrition in infancy and childhood, either over- or undernutrition, followed subsequently by overnutrition; (2) psychological factors, possibly involving emotional deprivation in childhood; (3) cultural or social norms regarding dietary restraint and attitudes to fatness that may be acquired during childhood.
\end{abstract}

Obesity: Socio-economic status: Longitudinal studies: Behaviour

Increasingly, we are appreciating that risk factors occurring in adult life provide insufficient explanation for adult health outcomes, and that factors occurring at different life stages need to be considered. To some extent this life-course approach is better established in obesity research than in other areas, but even here the role of childhood factors is not well understood. Potentially, there are several early life factors that might be involved in the development of obesity in adulthood (Parsons et al. 1999). To date, the best documented relationships are between parental size and adiposity in their offspring, and between childhood and adult fatness (Power et al. 1997). Evidence is less complete for other factors, such as childhood diet and physical (in)activity, and it is not clear whether these factors influence adult obesity because of their effect on behaviours in adulthood.

Unravelling the different life-course relationships involved in the development of obesity will be challenging, since the influence of different factors could be affected by their timing and duration, and also whether other cofactors are present. For example, in relation to timing of exposure, a factor occurring in early life may create biological and/or psychological vulnerability to later obesity. Although critical periods have been proposed in obesity development (gestation and early infancy, the period of adiposity rebound that occurs between ages 5 and 7 years, and adolescence), the mechanisms involved are not well understood (Dietz, 1994). An additional consideration is the duration of exposure to a particular risk(s), with small excesses for diet or physical inactivity having potentially important effects over a long time period. Finally, interactions between factors at different life stages could also be operating with, for example, a combination of early and later life risks influencing whether an individual becomes obese in adulthood.

Recently, we have reviewed the evidence on the role of childhood predictors of adult obesity, examining the influence of parental fatness, social factors, intrauterine

Abbreviation: SES, socio-economic status.

*Corresponding author: Dr Chris Power, fax +44 (0)20 7242 2723, email c.power@ich.ucl.ac.uk 
growth, timing of maturation, physical activity, dietary factors and other behavioural and psychological factors (Parsons et al. 1999). This is the most comprehensive review of research on childhood factors undertaken to date. Although there is general acceptance that diet and activity play a role in the development of obesity, the review found no clear evidence for an effect of infant feeding or direct measures of diet in childhood. There was inconsistent but suggestive evidence for a protective effect of activity in childhood on later fatness. However, studies investigating the role of diet or activity were generally small and included diverse methods of risk-factor measurement. Given that both childhood dietary intake and physical activity are very difficult to measure, it is perhaps not so surprising that conclusive evidence on the role of these factors has been elusive. It is for this reason that large epidemiological studies of early life environment and adult disease have tended to rely on indicator variables of nutritional status, such as birth weight, childhood leg length and height (Barker, 1992, 1994; Frankel et al. 1996; Gunnell et al. 1998).

\section{Socio-economic status of origin and adult obesity}

Further progress in understanding the role of nutrition and physical (in)activity in childhood in relation to adulthood obesity is limited by the inherent methodological problems of measuring these factors over extended periods of the life course. Meanwhile, it will be important to consider indirect measures of early life environment that provide clues as to the timing of aetiological influences on adult obesity. One such indicator variable is socio-economic status (SES) measured at different life stages and which has now been investigated in several studies. The present paper draws on evidence from these studies of SES to further understand whether conditions in childhood have an impact on later obesity.

Most interestingly in our review of childhood predictors of adult obesity was the consistent finding that both men and women with lower SES origins had a greater risk of adult obesity than those from higher SES backgrounds (Parsons et al. 1999). This finding contrasts with the evidence from cross-sectional studies in which SES trends are evident only for adult women and not for men or for children. Since the longitudinal relationships may be suggesting that socioeconomic environment in childhood is important in the development of adult obesity, it is worth reviewing some of the evidence.

First, to illustrate the cross-sectional relationship between adult SES and BMI, data from the Health Survey for England for 1996 show a clear social-class gradient in the prevalence of obesity (BMI > 30) among adult women, with the age-standardized prevalence for social class V $(25 \%)$ being almost twice that for social class I (14\%). There is, however, no clear pattern in men (Prescott-Clark \& Primatesta, 1998a).

These cross-sectional data for England are consistent with the general findings from a comprehensive review of SES and obesity, published 10 years ago, which included 144 studies from all over the world, of men, women and/or children (Sobal \& Stunkard, 1989). Despite the fact that these studies used a range of measures of SES and fatness, and spanned a period of 45 years, a strong negative relationship between SES and fatness was obvious in women across the developed world, such that fatness increased from higher social groups (professional and managerial) to lower social group (unskilled manual). Of fifty-four studies of women, $85 \%$ demonstrated a negative relationship, $13 \%$ no relationship and only $2 \%$ a positive relationship. Among men and children, however, the relationship was far less consistent, with studies more evenly spread over positive, negative and no relationships. In stark contrast, in developing countries, not a single study found an inverse relationship between SES and fatness in women. Indeed, the vast majority reported a positive relationship in both men and women, and in children.

However, cross-sectional data do not indicate the presence and direction of causality. A cross-sectional relationship in adulthood could be affected by reverse causation (whereby adiposity influences social position rather than the reverse), and there is some evidence for this possibility, with greater fatness leading to downward social mobility and thereby to lower SES (Gortmaker et al. 1993; Sargent \& Blanchflower, 1994). Whereas a longitudinal relationship, i.e. between SES in early life and adult obesity, cannot be explained by reverse causality.

In our review of childhood predictors of adult obesity we found twelve studies that examined the influence of SES in childhood on fatness in adulthood, with a duration of between 10 and approximately 55 years (Parsons et al. 1999). All studies examined the influence of SES, based on either parent(s) occupation (Charney et al. 1976; Ravelli \& Belmont, 1979; Teasdale et al. 1990; Lissau-Lund-Sorensen \& Sorensen, 1992; Blane et al. 1996; Wannamethee et al. 1996; Power \& Matthews, 1997), parent(s) education (Garn et al. 1991; Lissau-Lund-Sorensen \& Sorensen, 1992; Rasmussen \& Johansson, 1998), a composite of the two variables (Braddon et al. 1986; Goldblatt et al. 1965), or family income (Garn et al. 1981; Arnesen \& Forsdahl, 1985).

Of five studies of women, four found a negative relationship (Goldblatt et al. 1965; Garn et al. 1981; Braddon et al. 1986; Power \& Matthews, 1997) and one found no relationship (Arnesen \& Forsdahl, 1985) between SES and subsequent fatness. Nine studies included men, and of these studies eight observed a negative relationship (Goldblatt et al. 1965; Ravelli \& Belmont, 1979; Garn et al. 1981; Braddon et al. 1986; Blane et al. 1996; Wannamethee et al. 1996; Power \& Matthews, 1997; Rasmussen \& Johansson, 1998) and one found no relationship (Arnesen \& Forsdahl, 1985). Four studies analysed data from men and women combined; of these studies three showed a negative relationship (Charney et al. 1976; Teasdale et al. 1990; Hardy et al. 1998), and the other study showed either a negative or no relationship depending on the SES measure (Lissau-Lund-Sorensen \& Sorensen, 1992).

Data from the 1958 British birth cohort illustrate the longitudinal relationship, with mean BMI at age 33 years increasing from $23.6 \mathrm{~kg} / \mathrm{m}^{2}$ among women born into social classes I and II (professional and managerial) to $24.9 \mathrm{~kg} / \mathrm{m}^{2}$ in women from social classes IV and V (unskilled manual) backgrounds; in men the range was from 25.0 to $26 \cdot 1 \mathrm{~kg} / \mathrm{m}^{2}$ 
(Power \& Matthews, 1997). In another study, which was located in the west of Scotland, no relationship was found between own occupational class and mean BMI, whereas a graded relationship emerged in relation to father's social class from classes I and II (mean BMI $25.0 \mathrm{~kg} / \mathrm{m}^{2}$ ) to IV and $\mathrm{V}\left(25.4 \mathrm{~kg} / \mathrm{m}^{2}\right.$; Blane et al. 1996).

Social trends from studies of SES in childhood and subsequent adiposity within childhood were broadly similar to the trends emerging for adult obesity, with the majority of studies finding an negative relationship between SES and fatness in both sexes (Parsons et al. 1999).

Overall, the longitudinal studies show that in both males and females there is a remarkably consistent negative relationship between SES in childhood and subsequent fatness. Of a total of twenty-one longitudinal studies, seventeen found a negative relationship between a measure of SES and fatness at least 1 year later. The only study showing no relationship with fatness in adulthood $(\geq 18$ years) was based on retrospectively reported data on economic conditions in childhood which might account for the lack of a relationship (Arnesen \& Forsdahl, 1985). The major trend to emerge is that SES in early life is important, perhaps more important than SES in adulthood, although there are too few studies that examine SES longitudinally at different life stages.

\section{Explanations for the relationship between socio-economic status of origin and adult obesity}

The relationship between SES of origin and adult obesity is intriguing and, potentially at least, offers clues as to the timing of some of the factors contributing to the development of obesity. Several alternative explanations for the relationship can be postulated, with the most parsimonious explanation being that environment in early life (for which SES of origin is a proxy measure) has a longterm impact on obesity later in adulthood. This explanation is consistent with the hypothesis that there are critical periods involved in obesity development (Dietz, 1994), although it remains to be seen how the three specific periods relate to the SES association. Within the general explanation that environment in early life has a long-term impact on obesity, there are several factors that could be involved. However, before discussing these factors it is necessary to consider a further potential explanation, i.e. SES could be acting as a confounding factor.

\section{Confounding?}

In this life-course context, SES of origin might act as a confounding factor in the relationship between influences, such as parental body size, that pre-date the early life environment of their offspring. SES of origin might be associated with later obesity if it is simultaneously related to parental body size, which is a primary influence on an individual's risk of obesity. Few studies have allowed for parental BMI when examining the SES of origin-adult obesity relationship and, consequently, we cannot yet exclude the possibility that parental BMI accounts for this relationship.
SES might also be acting as a confounding factor in the relationship between birth weight and adult obesity, although it could also be argued that birth weight represents a specific component of the early life environment explanation. Irrespective of whether the relationship is regarded as confounding or part of the early environment, the associations observed between SES, birth weight and adult obesity are paradoxical. Obesity, as represented by BMI, appears to increase with increasing birth weight; but birth weight is related to SES such that poorer prenatal growth is evident among those born into less-advantaged SES families. So if birth weight were to account for the SES of origin-adult fatness relationship we would expect heavier weight at birth to be associated with lower-SES family background. But this expected pattern is the opposite of the observed pattern, with lighter weight at birth among those born into less-advantaged SES.

\section{Long-term effect of early environment?}

More direct measurement of nutrition in utero, for which birth weight is only a crude index, would be useful in establishing whether fetal undernutrition explains the relationship between SES of origin and adult obesity. There are, however, few studies that can shed light on the role of maternal nutrition. One of the few existing studies, the Dutch Hunger Winter study (Ravelli et al. 1976), suggests that effects on obesity depend on the timing of nutritional deprivation; exposure to famine in the first trimester of pregnancy was found to increase the risk of obesity in early adulthood, whereas exposure during the last trimester and first months of life reduced the risk. Extrapolation to lessextreme conditions is not clear given the increased infant mortality, prematurity and malformation rates that occur during famine.

A further possibility is that nutrition in infancy and childhood, either over- or undernutrition, is a significant factor explaining the SES of origin-adult obesity relationship. The studies of infant feeding method are of relevance here, in view of earlier concerns that bottlefeeding might result in overnutrition. This concern had arisen primarily because bottle-fed infants tended to be heavier than breast-fed infants (Department of Health and Social Security, 1974), and it was thought that the former were less likely to be able to regulate their intake. However, studies assessing the effect of infant feeding method over longer periods provide no support for the argument that bottle-feeding results in increased fatness (Parsons et al. 1999). To date there is only one study that assesses this relationship through to adulthood, and it found increased levels of adult fatness in association with breast-feeding (Marmot et al. 1980). Until we have confirmation of the long-term relationship between infant feeding, SES of origin and adult obesity, it is not at all clear whether feeding method is the pertinent factor in early life that relates to the SES of origin-adult obesity relationship.

With respect to the role of undernourishment in infancy and childhood, it could be the combination of undernourishment in early life followed by relative overnourishment later on that is important. Studies of 
populations undergoing nutritional transition are of relevance to this issue, particularly in their focus on childhood stunting. Whilst there are concerns regarding appropriate reference standards and definitions of obesity (Trowbridge et al. 1987), cross-sectional studies suggest that childhood stunting is associated with an increased prevalence of overweight (Popkin et al. 1996). For example, the income-adjusted risk ratios of being overweight for a stunted child ranged from 1.7 in Brazil to 7.8 in Russia (Popkin et al. 1996). It has been argued that when poor socio-economic conditions prevail overweight is not expressed, but with a rapid shift from nutritional scarcity to abundance, overweight emerges to co-exist with childhood stunting. Although these relationships are specific to populations undergoing rapid economic change, the importance of changing SES conditions may also apply to adults in developed countries. Even within a developed country, such as the UK, those in the lowest SES groups have poor prenatal growth signified by lower birth weight and, postnatally, slower growth and shorter stature (for example, see Wright et al. 1994). These well-known social trends are consistent with an explanation for the SES of origin-adult obesity relationship which involves a combination of poor growth in early life with subsequent nutritional abundance.

So far, the focus here is on nutrition as the likely underlying factor involved in the SES of origin-adult obesity relationship, but other primarily social and psychological processes may be operating. One possible explanation is represented by an early psychosomatic theory of obesity (Kaplan \& Kaplan, 1957) which emphasized a link between early childhood experiences with eating and comfort. Relatedly, other investigators have focused on self-esteem as a factor contributing to the development of obesity (French et al. 1995). Psychological characteristics, formed during childhood, may turn out to have a long-term impact on obesity, but the evidence to date is fragmentary and not entirely consistent (Parsons et al. 1999). However, there is some suggestive evidence that factors related to emotional development in early life might play a role in the development of obesity. For example, Lissau \& Sorensen (1994) report odds ratios for obesity at ages 20-21 years of $7 \cdot 1$ (95 \% CI 2.6, 19.3) for those perceived to have no parental support earlier in their life at ages 9-10 years compared with others; and of 9.8 (95\% CI 3.5, 28.2) for those assessed by their teachers as dirty and neglected ( $v$. average children). The authors speculate that parental neglect leads to psychological states in the offspring that affect their energy balance by altering behaviour (overeating and physical inactivity) or hormone balances, influencing fat accumulation. A possible pathway linking psychological states and obesity involves the hypothalamic-pituitaryadrenocortical system, which responds to stressful or threatening situations by altering hormone levels. There is some evidence for raised baseline cortisol levels in children with extreme shy or anxious or internalizing behaviours (Kagan et al. 1987), and also possibly in children demonstrating angry or aggressive behaviour. Increased cortisol promotes activity of lipid-accumulating enzymes in visceral fat and, in adults, is associated with an elevated waist: hip value (Bjorntorp, 1991). Although the causal pathway remains uncertain, emotional deprivation and psycho-social stress in childhood might lead to imbalances in the stress-response system, which in turn predisposes to (visceral) obesity. Further confirmation is needed on the relationship between parental neglect and adult obesity, in studies that clarify the associations using more direct measures of self-esteem and emotional deprivation during childhood. It is not yet clear, however, whether such psychological characteristics could account for the SES of origin-adult obesity relationship. Adverse material circumstances and life events are known to cluster in lowerSES families, but the effect of these factors on self-esteem and other psychological states during childhood is not well established.

Alternatively, the SES of origin-adult obesity relationship could signify differences in cultural or social norms, with the values of life and associated pressures to remain thin becoming established early in life in association with SES of origin. Dieting is more common among women of higher SES (Jeffery et al. 1991), and their scores on dietary restraint scales are higher (Jeffery et al. 1996). Among American women, those in the highest income group reported that a $5.0 \mathrm{~kg}(11 \mathrm{lb})$ gain in weight would prompt them to take action to reduce weight, whereas those in the lowest income group reported having to gain $9.1 \mathrm{~kg}(20 \mathrm{lb})$ before they would do something about it (Jeffery et al. 1996). In the same study, high-income women were more likely to use 'healthy' weight-control practices such as reducing energy and fat intakes, and increasing exercise. Women in lower-income groups tended to report more frequent use of 'unhealthy' weight-control practices, e.g. fasting, skipping meals and vomiting. In contrast, the extremes of dieting manifested in eating disorders such as anorexia nervosa and bulimia are believed to occur more frequently in higher-SES groups (Hsu, 1996), although a recent review refutes this argument (Gard \& Freeman, 1996). The prevalence of dieting in adolescents, particularly girls, is high (Sobal \& Stunkard, 1989; Prescott-Clarke \& Primatesta, 1998b), and data from the USA indicate that the relationship observed with SES in women may already be present in teenage girls, with those from higher-SES groups dieting more than those from lower-SES groups (Rosen \& Gross, 1987). Another study reported the desire to be thin among adolescent girls was greater among those from higher-income families, although there was little variation with family income among boys (Dornbusch et al. 1984). Rosenbaum (1979) found that in adolescence girls were already extremely aware that attractiveness in women is highly valued by society, and equated thinness with attractiveness. There is evidence to suggest that even children reflect societies' values of slimness, with social isolation and peer problems more common in fatter children (Stunkard \& Burt, 1967). Children tend to demonstrate strongly negative attitudes to obesity, particularly in higher-social-status schools (Wardle et al. 1995). SES differences in cultural norms are a potential explanation as to why individuals from families of 'manual' origin are more likely than those from 'non-manual' origins to both become overweight and retain their overweight through to early adulthood (Power \& Moynihan, 1988). 


\section{Future research}

The relationship between SES of origin and obesity in adult life appears to be a robust finding across different population samples. A plausible explanation for this finding is that factors in early life, such as undernutrition and emotional deprivation, may have detrimental effects on adult body size in the current environment of nutritional abundance. It is not clear whether early life factors contribute to the secular increase in obesity, but nonetheless the relationship with SES of origin deserves further attention in longitudinal growth studies. A major conclusion of our systematic review of childhood predictors of adult obesity was that there is a paucity of evidence on the influence of early life factors on adult obesity (Parsons et al. 1999). This conclusion is especially valid for studies spanning an extended period from childhood to adulthood. Several limitations of previous work need to be addressed in future research, including the failure to take adequate account of confounding factors, definition and measurement of risk factors and outcomes, and, finally, potential publication bias. The role of infant feeding, undernutrition (as indexed by stunting), and behavioural and psychological factors are poorly researched areas that warrant attention in future studies. Moreover, too little is known also about interactions between factors at different life stages. Large gaps remain in current knowledge concerning the reasons why weight control varies with SES, especially in women, and how societal values for slimness are transmitted to children. Differences in attitudes to body shape, knowledge and use of weight-control practices, and access to means of lifestyle change, all deserve further exploration.

\section{Acknowledgements}

Part of this work is based on our review of 'Childhood predictors of adult obesity' which was funded under the joint Department of Health/Medical Research Council Nutrition Initiative; the views expressed in this publication are those of the authors and not necessarily those of the sponsors.

\section{References}

Arnesen E \& Forsdahl A (1985) The Tromso heart study: coronary risk factors and their association with living conditions during childhood. Journal of Epidemiology and Community Health 39, 210-214.

Barker DJP (1992) Fetal and Infant Origins of Adult Disease. London: BMJ Publishing Group.

Barker DJP (1994) Mothers, Babies, and Disease in Later Life. London: BMJ Publishing Group.

Bjorntorp P (1991) Visceral fat accumulation: the missing link between psychosocial factors and cardiovascular disease? Journal of Internal Medicine 230, 195-201.

Blane D, Hart CL, Smith GD, Gillis CR, Hole DJ \& Hawthorne VM (1996) Association of cardiovascular disease risk factors with socioeconomic position during childhood and during adulthood. British Medical Journal 313, 1434-1438.

Braddon FE, Rodgers B, Wadsworth ME \& Davies JM (1986) Onset of obesity in a 36 year birth cohort study. British Medical Journal 293, 299-303.
Charney E, Goodman HC, McBride M, Lyon B \& Pratt R (1976) Childhood antecedents of adult obesity. Do chubby infants become obese adults? New England Journal of Medicine 295, $6-9$.

Department of Health and Social Security (1974) Present Day Practice in Infant Feeding. Report on Health and Social Subjects no. 9. London: HM Stationery Office.

Dietz WH (1994) Critical periods in childhood for the development of obesity. American Journal of Clinical Nutrition 59, 955-959.

Dornbusch SM, Carlsmith JM, Duncan PD, Gross RT, Martin JA, Ritter PL \& Siegel-Gorelick B (1984) Sexual maturation, social class, and the desire to be thin among adolescent females. Journal of Developmental and Behavioral Pediatrics $\mathbf{5}$, 308-314.

Frankel S, Elwood P, Sweetnam P, Yarnell J \& Davey Smith G (1996) Birthweight, body mass index in middle age, and incident coronary heart disease. Lancet 348, 1478-1480.

French SA, Story M \& Perry CL (1995) Self-esteem and obesity in children and adolescents: a literature review. Obesity Research $\mathbf{3}$, 479-490.

Gard MC \& Freeman CP (1996) The dismantling of a myth: a review of eating disorders and socioeconomic status. International Journal of Eating Disorders 20, 1-12.

Garn SM, Hopkins PJ \& Ryan AS (1981) Differential fatness gain of low income boys and girls. American Journal of Clinical Nutrition 34, 1465-1468.

Garn SM, Sullivan TV \& Hawthorne VM (1991) The juvenileonset, adolescent-onset and adult-onset obese. International Journal of Obesity 15, 105-110.

Goldblatt PB, Moore ME \& Stunkard AJ (1965) Social factors in obesity. Journal of the American Medical Association 192, 97-101.

Gortmaker SL, Must A, Perrin JM, Sobol AM \& Dietz WH (1993) Social and economic consequences of overweight in adolescence and young adulthood. New England Journal of Medicine 329, $1008-1012$.

Gunnell DJ, Davey Smith G, Frankel S, Nanchahal K, Braddon FEM, Pemberton J \& Peters TJ (1998) Childhood leg length and adult mortality: follow up of the Carnegie (Boyd Orr) Survey of Diet and Health in Pre-war Britain. Journal of Epidemiology and Community Health 52, 142-152.

Hardy R, Wadsworth M \& Kuh D (1998) Association between childhood obesity and social class across the life course in a British national cohort. Journal of Epidemiology and Community Health 52, 693 Abstr.

Hsu LK (1996) Epidemiology of the eating disorders. Psychiatric Clinics of North America 19, 681-700.

Jeffery RW, French SA, Forster JL \& Spry VM (1991) Socioeconomic status differences in health behaviors related to obesity: the Healthy Worker Project. International Journal of Obesity 15, 689-696.

Jeffery RW, French SA, Forster JL \& Spry VM (1996) Socioeconomic status and weight control practices among 20- to 45-year-old women. American Journal of Public Health 86, $1005-1010$.

Kagan J, Reznick JS \& Snidman N (1987) The physiology and psychology of behavioral inhibition in children. Child Development 58, 1459-1473.

Kaplan HI \& Kaplan HS (1957) The psychosomatic concept of obesity. Journal of Nervous and Mental Disease 125, 181-201.

Lissau I \& Sorensen TI (1994) Parental neglect during childhood and increased risk of obesity in young adulthood. Lancet 343, 324-327.

Lissau-Lund-Sorensen I \& Sorensen TI (1992) Prospective study of the influence of social factors in childhood on risk of overweight in young adulthood. International Journal of Obesity 16, $169-175$. 
Marmot MG, Page CM, Atkins E \& Douglas JW (1980) Effect of breast-feeding on plasma cholesterol and weight in young adults. Journal of Epidemiology and Community Health 34, 164-167.

Parsons T, Power C, Logan S \& Summerbell C (1999) Childhood predictors of adult obesity: a systematic review. International Journal of Obesity 23, Suppl. 8, 1-107.

Popkin BM, Richards MK \& Montiero CA (1996) Stunting is associated with overweight in children of four nations that are undergoing the nutrition transition. Journal of Nutrition 126, 3009-3016.

Power C, Lake JK \& Cole TJ (1997) Measurement and long-term health risks of child and adolescent fatness. International Journal of Obesity 21, 507-526.

Power C \& Matthews S (1997) Origins of health inequalities in a national population sample. Lancet 350, 1584-1589.

Power C \& Moynihan C (1988) Social class and changes in weightfor-height between childhood and early adulthood. International Journal of Obesity 12, 445-453.

Prescott-Clarke P \& Primatesta P (editors) (1998a) Health Survey for England '96. London: HM Stationery Office.

Prescott-Clarke P \& Primatesta P (editors) (1998b) Health Survey for England: The Health of Young People '95-97. London: HM Stationery Office.

Rasmussen F \& Johansson M (1998) The relation of weight, length and ponderal index at birth to body mass index and overweight among 18-year-old males in Sweden. European Journal of Epidemiology 14, 373-380.

Ravelli GP \& Belmont L (1979) Obesity in nineteen-year-old men: family size and birth order associations. American Journal of Epidemiology 109, 66-70.

Ravelli GP, Stein ZA \& Susser MW (1976) Obesity in young men after famine exposure in utero and early infancy. New England Journal of Medicine 295, 349-353.
Rosen JC \& Gross J (1987) Prevalence of weight reducing and weight gaining in adolescent girls and boys. Health Psychology 6, 131-147.

Rosenbaum M (1979) The changing body image of the adolescent girl. In Female Adolescent Development, pp. 235-252 [M Sugar, editor]. New York: Brunner/Mazel.

Sargent JD \& Blanchflower DG (1994) Obesity and stature in adolescence and earnings in young adulthood. Analysis of a British birth cohort. Archives of Pediatrics and Adolescent Medicine 148, 681-687.

Sobal J \& Stunkard AJ (1989) Socioeconomic status and obesity: a review of the literature. Psychological Bulletin 105, 260-275.

Stunkard A \& Burt V (1967) Obesity and the body image. II. Age at onset of disturbances in the body image. American Journal of Psychiatry 123, 1443-1447.

Teasdale TW, Sorensen TI \& Stunkard AJ (1990) Genetic and early environmental components in sociodemographic influences on adult body fatness. British Medical Journal 300, 1615-1618.

Trowbridge FL, Marks JS, Lopez de Romana G, Madrid S, Boutton TW \& Klein PD (1987) Body composition of Peruvian children with short stature and high weight-for-height. II. Implications for the interpretation for weight-for-height as an indicator of nutritional status. American Journal of Clinical Nutrition 46, 411-418.

Wannamethee SG, Whincup PH, Shaper G \& Walker M (1996) Influence of fathers' social class on cardiovascular disease in middle-aged men. Lancet 348, 1259-1263.

Wardle J, Volz C \& Golding C (1995) Social variation in attitudes to obesity in children. International Journal of Obesity 19, $562-569$.

Wright CM, Waterson A \& Aynsley-Green (1994) Effect of deprivation on weight gain in infancy. Acta Paediatrica 83, 357-359. 